\title{
ICH Common Technical Document
}

National Cancer Institute

\section{Source}

National Cancer Institute. ICH Common Technical Document. NCI Thesaurus. Code C142575.

A record format agreed upon by the International Council for Harmonisation to organize applications to regulatory authorities for registration of pharmaceuticals for human use. $(\mathrm{ICH})$ 